\title{
Ensino remoto em tempos de pandemia -um estudo de caso do Instituto Federal do
}

\section{Sul de Minas- campi Passos}

\author{
Remote teaching in times of pandemic - a case study of the Federal Institute of the South of Minas - \\ campi Passos \\ Enseñanza remota en tiempos de pandemia - Estudio de caso del Instituto Federal del Sur de Minas \\ - campi Passos
}

José Carlos Guimarães Junior

ORCID: https://orcid.org/ 0000-0002-8233-2628 Universidade do Estado do Amazonas, Brasil Rede Bionorte, Brasil E-mail: profjc65@hotmail.com

Aline dos Santos Moreira de Carvalho

ORCID: https://orcid.org/0000-0001-9965-9566 Universidad Columbia Del Paraguay, Paraguai E-mail: bioaline2017@yahoo.com

Breno Giovanni Adaid-Castro ORCID: https://orcid.org/0000-0002-9856-4263 Universidade de Brasília, Brasil E-mail: brenoadaid@gmail.com

Pedro Carlos Pereira

ORCID: https://orcid.org/0000-0003-4646-0080 Universidade Federal Rural do Rio de Janeiro, Brasil Universidad Columbia Del Paraguay, Paraguai E-mail: pecape@ig.com.br

\begin{abstract}
Resumo
$\mathrm{O}$ artigo tem como objetivo identificar as percepções que os alunos do Instituto Federal do Sul de Minas- Campi Passos, durante a realização do primeiro semestre de 2021, especificamente nas disciplinas de Teoria Geral da Administração I. Para a construção desse material fez-se necessário a elaboração de um questionário semiestruturado, contendo 3 (três) perguntas fechadas, disponibilizado via Google Class, que foi encaminhado aos alunos, onde o tempo especificado pra resposta foi de (5) dias, durante o mês de julho de 2021, onde todos os alunos responderam, somando um total de 44 alunos. Na conclusão verificou-se que o modelo de ministração dessa disciplina permitiu uma avaliação importante na metodologia utilizada, o que oferece subsídios para uma avaliação global por parte do professor e serve de norte para os gestores da Instituição. Além disso, identificou-se os pontos de excelência no processo ensino aprendizagem e os ajustes necessários a serem providenciados, que se sugere que sejam aplicadas as outras disciplinas dos demais cursos que são ofertados pela Instituição, respeitando as metodologias utilizadas pelos demais professores.
\end{abstract}

Palavras-chave: Ensino remoto; Instituto Federal do Sul de Minas; Passos

\begin{abstract}
The article aims to identify the perceptions that students at the Federal Institute of Southern Minas Gerais - Campi Passos, during the first semester of 2021, specifically in the subjects of General Theory of Administration I. For the construction of this material it was necessary the elaboration of a semi-structured questionnaire, containing 3 (three) closed questions, available via Googlegass, which was sent to the students, where the specified time for the answer was (5) days, during the month of July 2021, where all students responded, totaling 44 students. In conclusion, it was found that the model of teaching of this discipline allowed an important assessment in the methodology used, which offers subsidies for a global assessment by the teacher and serves as a guide for the Institution's managers. In addition, the points of excellence in the teaching-learning process and the necessary adjustments to be provided were identified, which suggests that the other subjects of the other courses offered by the institution be applied, respecting the methodologies used by the other teachers.
\end{abstract}

Keywords: Remote teaching; Instituto Federal do Sul de Minas; Passos.

\section{Resumen}

El artículo tiene como objetivo identificar las percepciones que tuvieron los estudiantes del Instituto Federal del Sur de Minas Gerais - Campi Passos, durante el primer semestre de 2021, específicamente en las asignaturas de Teoría 
General de la Administración I. Para la construcción de este material fue necesaria la elaboración de un cuestionario semiestructurado, conteniendo 3 (tres) preguntas cerradas, disponible vía Google Class, el cual fue enviado a los estudiantes, donde el tiempo especificado para la respuesta fue de (5) días, durante el mes de julio de 2021, donde todos los estudiantes respondió, totalizando 44 estudiantes. En conclusión, se encontró que el modelo de enseñanza de esta disciplina permitió una valoración importante en la metodología utilizada, la cual ofrece subsidios para una evaluación global por parte del docente y sirve de guía para los directivos de la Institución. Además, se identificaron los puntos de excelencia en el proceso de enseñanza-aprendizaje y los ajustes necesarios a realizar, lo que sugiere que se apliquen las demás asignaturas de los demás cursos que ofrece la institución, respetando las metodologías utilizadas por los demás docentes.

Palabras clave: Enseñanza a distancia; Instituto Federal do Sul de Minas; Passos.

\section{Introdução}

O processo de intermediação das tecnologias digitais, especificamente no segmento da educação, destacando na educação tecnológica, objeto desse case, sempre se constituiu em um grande incitamento a ser vencido na relação alunoprofessor.

Instigante esses desafios nos diversos cenários existentes, e assim destacamos o período que se refere a Pandemia do Coronavírus, por se evidenciar uma realidade que as Instituições de Ensino em todos os níveis de formação, apresentou inúmeras dificuldades, tais como os acessos e interações.

Segundo dados de pesquisas e leituras realizadas durante o período dessa pesquisa, identificou-se que essa foi, e ainda continua, sendo uma realidade em todo o planeta, e no Brasil, não acontece de diferente. Além disso, um percentual importante dos educadores foi pego de surpresa, no que se refere ao uso de domínio dessas tecnologias, que apesar de existentes há alguns anos, tiveram que passar por um breve processo de aprendizado dessas tecnologias.

A origem dessa pesquisa deu-se pela necessidade de ministrar a disciplina via remota, com os alunos do Instituto Federal de Educação do Sul de Minas, especificamente do Campi de Passos-MG, onde a partir de do mês de fevereiro de 2020, como a decretação da Pandemia em todo o planeta pela Organização Mundial da Saúde- OMS, o Brasil adere as orientações referentes as medidas protetivas para que evitasse o aumento no processo de contaminação da virose cada vez mais latente.

Assim, foi decretado restrições ao funcionamento de diversas atividades comerciais, não obstante, as Instituições de Ensino não ficaram fora desse processo, devendo em caráter de urgência, apresentarem metodologias e dinâmicas de ensino de forma remota.

Dessa forma, todas as disciplinas oferecidas em todos os cursos pelo Instituto Federal de Educação do Sul de MinasCampi Passos, passam a ser ofertados via remota, que é caracterizada pela forma de ensino onde é utilizada alguma ferramenta tecnológica, onde, em horários pré-determinados, os alunos se encontram com os professores de cada disciplina.

Ainda citando a OMS, cerca de $90 \%$ dos alunos em todo o planeta foram afetados pela suspensão das aulas presenciais e demais atividades em todos os setores; não obstante, países como Espanha e Estados Unidos, adotassem estratégicas, que em um primeiro momento, seria via remota; em um segundo momento, um modelo híbrido, onde as Instituições de Ensino organizassem suas atividades onde os alunos retornariam as aulas em dias alternados, até que fossem autorizada o retorno presencial das atividades acadêmicas.

O conceito de educação remota não é uma prática recente no contexto da educação Brasil, porém analisando-se em nível mundial, é uma práxis muito difundida e utilizada há décadas. No Brasil, o sistema de educação a distância existe há um bom tempo também, porém somente na última década é que sofreu um boom importante, tornado essa modalidade costumeira nos dias atuais.

Cabe distinguir a modalidade EAD- Educação a distância e Ensino Remoto, onde o primeiro é realizado $100 \%$ de forma virtual, podendo alguns centros de ensino deixar a disposição dos alunos, laboratórios e tutores em suas instalações. 
No caso do ensino remoto, modalidade essa que teve seu auge no período da Pandemia do Covid-19, tornou-se uma rotina a partir do mês de janeiro/fevereiro de 2020, estendendo-se até o final do ano de 2021, onde as atividades são realizadas de forma síncrona e assíncrona.

As aulas são realizadas na modalidade Web conferência, utilizando-se de ferramentas disponíveis nas plataformas da internet de forma gratuita.

Em regra, as universidades, faculdades, Institutos Federais de Educação, possuem seus próprios sistemas de controle de notas presenças, sendo que no caso desse estudo de caso, utilizou-se a ferramenta Googleclass, que é ofertada de forma gratuita aos seus usuários.

Segundo Fialho (2020), em abril de 2020, o governo de Minas Gerais instituiu o regime de tele trabalho, incluindo os profissionais da educação no rol de servidores públicos. Em 12 de maio, fechou as escolas e implementou um programa de educação remota cujo objetivo era reduzir o efeito derivado da interrupção das aulas presenciais, além de assegurar a manutenção da formação escolar, mesmo que virtualmente, e dessa forma foi designado como medida para o restabelecimento do calendário escolar interrompido na modalidade presencial em virtude do cenário ocasionado pela pandemia da Covid-19, o Regime de Estudos não presenciais (Reanp) foi implementado pela Secretaria Estadual de Educação de Minas Gerais (SEE), por meio da resolução n. ${ }^{\circ} 4.310$.

\section{Fundamentação Teórica}

A modalidade de ensino remoto é normatizado e oferece segurança aos alunos tal qual no modelo presencial, e necessita oferecer material didático com qualidade garantir as atividades normais, tais quais as atividades presenciais, já que oferece todo o material didático utilizando-se as diversas plataformas digitais oferecidas em vários sistemas digitais.

Para uma instituição de ensino ofereça cursos à distância, seja na forma de graduação ou pós-graduação é necessário ter autorização do Ministério da Educação- MEC, e para seu credenciamento devem ser seguidos as orientações do Artigo 80 da lei $n^{\circ} 9.394$ e o Decreto $n^{\circ} 9.057$.

A Lei $n^{\circ}$ 9.394, foi criada em 20/12/96, onde é estipulado no artigo 80 que o poder público deve incentivar o desenvolvimento e a veiculação de programas de Educação a Distância em todos os níveis, Graduação e Pós-Graduação, à exceção dos cursos de Mestrado e Doutorado, que já estão em fase de recebimento de propostas de projetos pedagógicos por parte das Universidades e Institutos de Ensino, pelo Mec., porém até o mês de julho de 2021, o Ministério da Educação ainda não estabeleceu um projeto que possa ser utilizado como padrão pelas Universidades habilitadas a utilizarem essa metodologia.

A União/Estado, é responsável também por regulamentar os requisitos para a realização de exames e registro de diploma relativos aos cursos à distância, onde as normas para produção, controle e avaliação dos programas de educação a distância e a autorização para sua implementação, caberão as Instituições de Ensino que os oferecem, podendo ocorrer parcerias e cooperação entre Instituições distintas.

Assim, o Decreto ${ }^{\circ}$ 9.057, editado em 25/05/2017, com o intuito de regulamentar o Artigo 80 da Lei $\mathrm{n}^{\circ} 9.394$, onde a diferença entre eles (decretos), é que a lei estabelece as diretrizes e bases da educação nacional no geral e o decreto é referente a sessão de educação de nível superior.

Assim, o decreto contempla que a modalidade a distância como sendo um modelo educacional que deve ocorrer com o uso de meios tecnológicos, oferecendo informações e a comunicação, para que os alunos possam desenvolver suas atividades em diversos lugares e tempos que desejarem, respeitando as orientações estipuladas nos regimentos dos cursos.

As Faculdades que oferecem cursos EAD, deverão por força de lei, oferecer aos alunos condições mínimas para que desenvolvam suas atividades acadêmicas com excelência e dentro de uma realidade de mercado. Dessa forma, nos dias atuais 
não é difícil de encontrar centros de ensino, seja com sede própria ou franquias, que oferecem suporte importante aos interessados em cursar via EAD.

A educação a distância é definida como "um tipo de método de instrução em que as condutas docentes acontecem à parte das discentes, de tal maneira que a comunicação entre o professor e o aluno se possa realizar mediante textos impressos, por meios eletrônicos, mecânicos ou por outras técnicas”. Moore e Kearsley, (1996, p. 206).

Ao entrarmos no século XXI, onde a Era da informação e ao acesso direito aos conteúdos eletrônicos é compartilhado em tempo real e com alcance mundial, a criação de ambientes educativos virtuais, onde ocorra interação on-line entre professores, alunos e tutores, devem ofertar o processo de interatividade contínua e simultânea, oferecendo aos estudantes, a possiblidade de acesso ao tempo que melhor lhes convier.

Nunes (1992) descreve que “o processo de educação/ensino a distância é um método racional de partilhar conhecimento, habilidades e atitudes, através da aplicação da divisão do trabalho e de princípios organizacionais, tanto quanto pelo uso extensivo de meios de comunicação, especialmente para o propósito de reproduzir materiais técnicos de alta qualidade, os quais tomam possível instruir um grande número de estudantes ao mesmo tempo, enquanto esses materiais durarem: É uma forma industrializada de ensinar e aprender.

A metodologia EAD deve ofertar instrumentos que estimulem o processo de ensino/aprendizagem, compartilhando conhecimentos, habilidades, atitudes e experiências, que tornarão possíveis o aprendizado e/ou aprimoramento dos conhecimentos dos estudantes.

Os conteúdos ofertados nessa modalidade exigem uma maior estruturação e preparo por parte dos docentes e discentes, pois nem todos os alunos tem acesso a algum meio de comunicação remota, em condições que os docentes oferecem para ministrar suas aulas durante os períodos letivos.

Assim, faz-se necessário uma diferenciação entre Educação a distância, já comentado, e Educação Remota, que está esteja diretamente relacionado ao uso de tecnologia, ou seja, sem o uso de acesso de instrumentos tecnológicos, torna-se impossível o estabelecimento dessa modalidade de ensino.

Essa modalidade de ensino ocorre com o uso de plataformas digitais já disponíveis, tais como Moodle, aplicativos como Hangouts, Meet, Zoom, redes sociais e demais ferramentas que são utilizadas para esses fins, onde são de domínio público e abertas ao público de forma gratuita, tornando-se, agora mais do que nunca, ferramentas inovadoras e necessárias para essa relação ensino/aprendizagem.

Em regra geral, as universidades e demais institutos de educação, estabelecem uma ferramenta padrão para se padronizar o processo de registro de aulas, notas e os demais controles, evitando assim que existam professores utilizando-se de plataformas distintas.

Alguns critérios de qualidade devem levados em consideração na hora de elaborar os conteúdos a serem ofertados, que permeiam as atividades integradoras e construtoras dos processos de ensino e aprendizagem, sendo que podemos destacar alguns pontos importantes a serem levados em consideração, tais como: promover uma participação ativa do estudante; ajudar o alunos a construir seu próprio conhecimento a partir da interação com seus colegas de turma; promoção e a formulação de indagações que possam levadas a investigação; incentivar os alunos a se expressarem, organizando e contrastando seus conhecimentos com seus aprendizados anteriores e suas experiências; incitar a aprendizagem autônoma; oportunizar a desenvolução de projetos de pesquisa para buscar respostas a determinadas indagações; providenciar a exploração de novos conteúdos através de recursos digitais e outras fontes de informação; organizar as informações pesquisadas obtidas, através de resumos, entendendo, relacionando e findando todos esses conteúdos de forma estruturada.

Sob a análise do ponto de vista didático, o professor, enfrenta um mesmo desafio no ensino remoto e na modalidade presencial, cabendo dessa forma toda a organização desses conteúdos, apresentando materiais de forma clara e objetiva. 
Sob o ponto de vista das habilidades, os professores devem preterir o domínio das ferramentas que serão utilizadas nas suas aulas, onde a comunicação pode ser síncrona (em tempo real) ou assíncrona (em tempo diferente); a utilização de recursos tecnológicos, digitais ou analógicos, como ferramentas de suporte ao processo ensino/aprendizagem.

Logicamente que os professores no seu dia a dia, no modelo convencional, já utilizam ferramentas tecnológicas, porém há de se destacar, que nesses tempos de Pandemia, o ensino remoto é a única opção ofertada aos alunos.

O Planejamento das aulas nesse sistema devem ser disponibilizados aos alunos na forma de gravação das aulas, utilizando-se dessa metodologia para que os alunos, caso queriam rever as aulas, possam ter acesso as aulas gravadas durante os encontros remotos.

\section{Metodologia}

A metodologia utilizada foi a aplicação de questionário, com perguntas fechadas, aos alunos da turma de Teoria Geral da Administração-TGA, ao final do $1^{\circ}$ semestre de 2021.

Assim, e tomando por base as definições de Vergara (1995), que define quanto aos fins; exploratória, esta investigação foi realizada tendo como desafio maior a identificação e a percepção dos alunos da referida turma, nessa realidade onde se utilizou a metodologia de ensino remota.

Tratando-se, portanto, esse estudo sobre a percepção dos alunos do Instituto Federal de Educação do Sul de MinasCampi Passos, da turma de TGA, onde foi definida a metodologia por acessibilidade, onde foram disponibilizados questionários, com perguntas fechadas, entre os dias 9 a 13 de agosto de 2021.

Para melhor atingir todo o universo de alunos dessa turma, 35 (trinta e cinco), foi criada uma atividade na sala do Classroom da própria turma, onde o questionário foi encaminhado a todos os alunos. Dessa forma, e sem muitas surpresas, todos os alunos responderam as indagações expressas no questionário.

Segundo Vergara (1995): Amostra por acessibilidade seleciona elementos pela facilidade de acesso a eles, longe de qualquer procedimento estatístico; e por tipicidade quando a amostra é constituída pela seleção de elementos que o pesquisador considere representativos de população-alvo, o que requer profundo conhecimento dessa população [...].

As respostas identificadas, foram analisadas e comentadas na parte que segue essa pesquisa, onde gerou-se gráficos representativos.

\section{Análise dos Dados Obtidos}

No que tange a percepção dos alunos no que se refere a metodologia de ensino das aulas, $65 \%$ dos alunos, uma maioria significativa, aprovou essa modalidade de ensino.

Observe a informação no gráfico abaixo: 
Gráfico 1 - Você gostou da forma de ensino remoto?

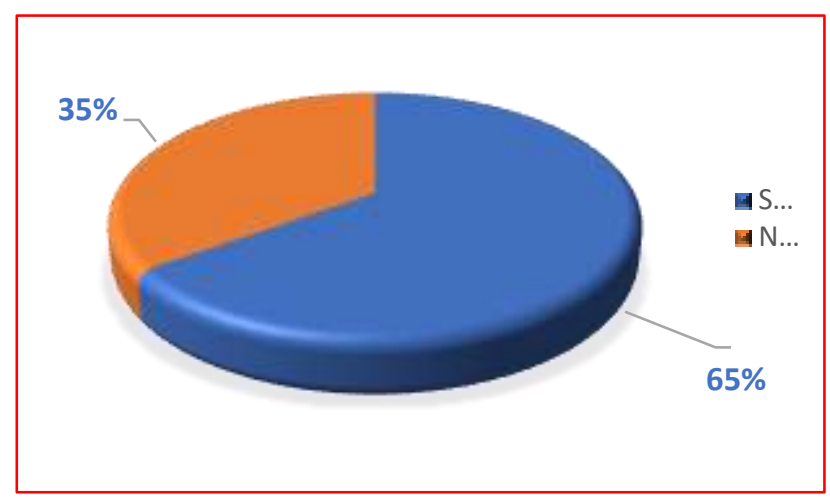

Fonte: Autores.

O grande desafio dos professores refere-se a forma de se repassar seus conteúdos utilizando-se essa modalidade de ensino, onde a escolha na didática, seja na forma de debates, filmes, fóruns e apresentação de seminários, é fator primordial para que se retenha e se estimule os alunos no decorrer das aulas.

Os alunos foram questionados quanto a participação nas aulas e os resultados obtidos, seguem abaixo:

Gráfico 2 - Quanto a participação nas aulas, você conseguiu participar de todas?

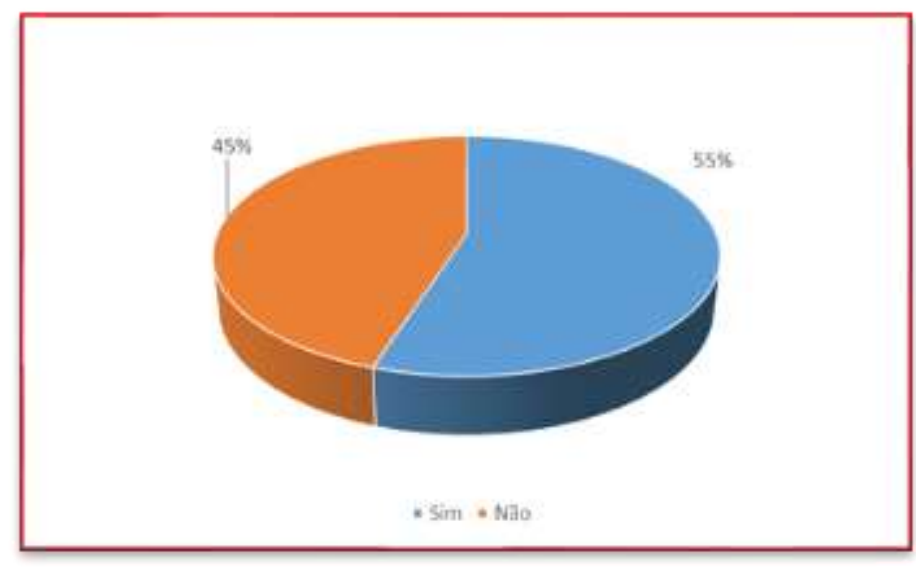

Fonte: Autores.

A participação dos alunos nas aulas remotas, identificadas no Gráfico 2, percebe-se que a maioria conseguiu participar das interações realizadas on-line; porém um percentual expressivo, de $45 \%$ dos alunos, não acompanhou todas as aulas, fato esse que foi urge uma pesquisa mais aprofundada dessa percepção. Alguns professores comentaram, de maneira informal durante a realização da pesquisa, que acreditam que a facilidade de que o aluno tem em estar "por trás" de uma câmera, pode simplesmente estar participando da sala, mas efetivamente não está acompanhando as aulas.

De qualquer forma, é um grande desafio para que os professores desenvolvam ou utilizem dinâmicas que oferecem algum tipo de "incentivo" aos alunos tornem-se mais participativos nos encontros on-line.

Os alunos foram questionados quanto a realização das atividades propostas durante as aulas remotas, o resultado segue: 
Gráfico 3 - Quanto as tarefas que os professores postavam, você fez todas?

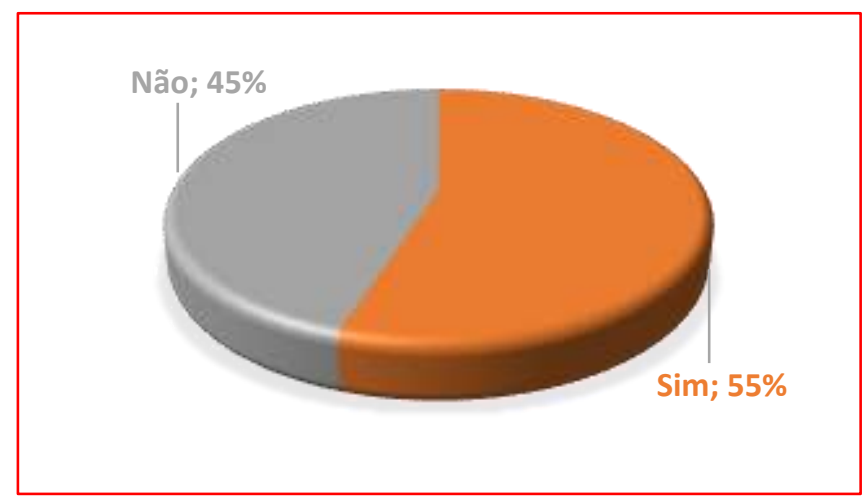

Fonte: Autores.

Em relação a realização das tarefas ofertadas pelo professor, 55\% dos alunos informaram que responderam as tarefas postadas, e $45 \%$ não.

As tarefas colocadas à disposição dos alunos para suas complementações, cabendo destaque de que os seminários não fazem parte dessas tarefas, foram indagações subjetivas, o que de alguma forma, acreditou-se que seria um desafio aos alunos responderem todas; porém não foi o que se identificou na pesquisa; talvez pelo fato de que acreditassem que com a quantidade de tarefas disponibilizadas, o somatório destas e o cálculo da média final, chegassem a uma média de aprovação.

Diante dessa informação, questionou-se se os alunos preferem aulas remotas ou presenciais.

Gráfico 4 - Você prefere as aulas remotas ou presenciais?

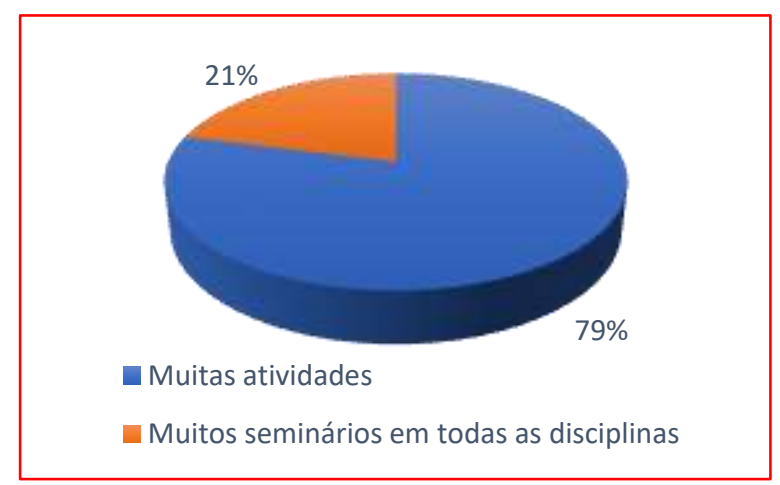

Fonte: Autores.

$\mathrm{Na}$ sua maioria, os alunos preferiram as aulas presenciais, talvez pelo fato de terem a oportunidade de sanarem suas dúvidas com mais proximidade aos professores, bem como o encontro presencial com os colegas.

O fato identificado é que, os gestores da Instituição devem ficar atentos a esse registro, no sentido de que prevejam o retorno presencial das aulas, logicamente seguindo todas as orientações emanadas pela Organização Mundial da Saúde - OMS.

Um ponto importante a ser explorado pela Instituição é que, pelo fato de que $35 \%$ dos alunos matriculados nos cursos presenciais, a modalidade a distância possa ser oferecida nos semestres seguintes, tendo em vista que existe definitivamente uma demanda importante para aulas via EAD, utilizando-se de metodologias ativas de Educação a Distância, embora já existam cursos que são oferecidos nessa modalidade no Instituto.

O excesso de atividades cobradas pelos professores são o ponto que chama mais atenção nessa análise, existindo alguns comentários informais por parte dos alunos e que, por uma questão ética não são citados na pesquisa, "alguns 
professores chegaram a passar atividades em todas as aulas, fazendo com que ao final de semana, ficássemos com tantas tarefas a serem cumpridas que praticamente não tínhamos mais tempo para absolutamente nada". R.B

Um debate importante surge nessa análise que se refere a quantidade de tarefas que são cobradas dos alunos nessa modalidade, porém, não coube nessa pesquisa a intenção de se explorar juntos aos professores, da real necessidade, ou não, de se oferecer tantas tarefas aos alunos, pois cabe a cada docente que saiba como dever cobrar seus conteúdos ministrados em sala de aula.

Não obstante, essa pesquisa serve de base para poder colocar no debate em reuniões pedagógicas, esse tema.

\section{Considerações Finais}

Como já referimos na introdução dessa pesquisa, a intenção foi apresentar as percepções dos alunos da turma de Teoria Geral da Administração do Instituto Federal de Educação do Sul de Minas, Campi Passos, no que se refere as aulas ofertadas no $1^{\circ}$ semestre do ano de 2021, quando o ensino remoto foi utilizado como alternativa para que as aulas continuassem na sua forma plena de forma eficiente e eficaz.

Assim, as respostas obtidas quando da aplicação do questionário serviu de base para tecer comentários a respeito do tema tratado nesse artigo, bem como ousar em promover algumas análises para reflexão, tanto por parte dos gestores dessa Instituição de Ensino, quanto aos professores e alunos.

Dessa forma, os regramentos básicos que o professor deva conhecer para ministrar as disciplinas remotamente é de grande valia para que produza resultados positivos de resposta de seus alunos em sala de aula e nos seus diversos aprendizados durante o semestre, buscando ativar à vontade em manter-se alertas durante a realização das aulas, utilizando-se dinâmicas e ferramentas que são oferecidas.

Não se pretender nessa pesquisa, oferecer subsídios para que se alterne de forma definitiva da modalidade presencial para a remota, visto que o objetivo foi de identificar as percepções dos alunos em relação a essa metodologia de ensino desse momento de pandemia, porém, há de se considerar essas metodologias de ensino, podem ser utilizadas de forma mais exequível quando do retorno as aulas na modalidade presencial.

Como sabemos, as mudanças dos processos organizacionais são difíceis, e surgem em contextos dolorosos, como é o caso da pandemia do Covid-19, e implicam em enormes desafios institucionais, pessoais e coletivos, na utilização de processos adaptativos, de mudança e de flexibilidade, além de inovação e de quebra de paradigmas.

E esse processo de uma provável mudança de filosofia educacional, reivindica políticas desafiadoras de formação docente e de uma definitiva apropriação digital, sendo que não deve ser instituída essa metodologia de forma radical e sim incremental.

Da mesma forma, a educação digital é um processo caracterizado pelo processo de conectividade eficaz, rapidez, fluidez, e da apropriação de ferramentas tecnológicas necessárias para suscitar processos educativos destinados a melhorar e a desenvolver a qualidade profissional dos professores.

E assim que na vertente dessa realidade, onde as necessidades em relação à docência remota é a única metodologia própria e segura, no que se refere a pandemia do Covid-19, e que deve-se oferecer e definir políticas para a criação de programas de formação e de capacitação para todos os agentes educativos direcionados para o desenvolvimento de projetos de formação e educação digital que permitam realizar uma adequada transição deste ensino remoto emergencial para uma educação digital em rede de qualidade. 


\section{Referências}

Arroyo, M. G. (2013). Currículo, território em disputa. (5a ed.), Vozes.

Brasil (2020). Ministério da Educação. Coronavírus: monitoramento nas instituições de ensino. http://portal.mec.gov.br/coronavirus

Brasil, (1996a). Lei no 9.394/96, de 20 de dezembro de 1996. Lei de Diretrizes e Bases da Educação Nacional. Diário Oficial da União, Brasília, DF, 1996. Presidência da República. Decreto $\mathrm{n}^{\circ}$ 9.057, de 25 de maio de 2017. Disponível em: < https://www.planalto.gov.br/ccivil_03/_Ato20152018/2017/Decreto/D9057.htm\#art24 . Lei nº 9.394, de 20 de dezembro de 1996. Estabelece Diretrizes e Bases da Educação Nacional. Brasília, 1996a.

Carmo, R. O. S. \& Franco, A. P. (2019). Da docência presencial à docência online: aprendizagens de professores universitários da educação a distância. Educação em Revista, 35:1-29. http://dx.doi.org/10.1590/0102-4698210399

Centro Regional de Estudos para o Desenvolvimento da Sociedade da Informação - CETIC.BR. (2016). Educação e tecnologias no Brasil: um estudo de caso longitudinal sobre o uso das tecnologias de informação e comunicação em 12 escolas públicas Comitê Gestor da Internet no Brasil

Costa, F. A. (2013). O potencial transformador das TIC e a formação de professores e educadores. In: Almeida, MEB, Dias, P, Silva, BD (Org.). Cenários de inovação para educação na sociedade digital. São Paulo: Loyola, p. 47-74.

Freire, P. (1996). Pedagogia da autonomia: saberes necessários à prática educativa. (34a ed.), Paz e Terra.

Fialho, L, M.F, \& Nascimento, k. A.S.do. A Experiência de Indexação da Revista Educação \& Formação. In: ABEC Meeting Live, 2020. Anais... São Paulo: Associação Brasileira de Editores Científicos, 2020.

Hodges, C, Moore, S, Lockee, B, Trust, T \& Bond, A. (2020). The Difference Between Emergency Remote Teaching and Online Learning. March 27. Obtido em 22 de agosto de 2020. https://er.educause.edu/articles/2020/3/the-difference-between-emergency-remote-teaching-and-online-learning

Lagarto, J. R. Inovação, TIC e sala de aula. In: Cavalheiri, A., Engerroff, S. N., \& Silva, J. C. (Org.). As novas tecnologias e os desafios para uma educação humanizadora. Santa Maria: Biblos, 2013, p. 133-158.

Lefevre, F., \& Lefevre, A. M. Depoimentos e discursos: uma proposta de análise em pesquisa social. Liber Livros, 2005.

Moore, M. G., \& Kearsley, G. (1996). Distance education: a systems view. United States: Wadsworth Publishing Company.

Nunes, E. D. Ciências sociais em saúde no Brasil: notas para a sua história. Educ. méd. Salud, 21(2): 106-15, 1992.

Organização Mundial da Saúde. (2011) Manual do AnthroPlus para computadores pessoais: Software para avaliação do crescimento de crianças e adolescentes no mundo. Genebra: Organização Mundial da Saúde. http://www.who.int/childgrowth/software/en/

Organização Mundial da Saúde. (2011) Manual do AnthroPlus para computadores pessoais: Software para avaliação do crescimento de crianças e adolescentes no mundo. Genebra: Organização Mundial da Saúde, http://www.who.int/childgrowth/software/en/

Palfrey, J, \& Gasser, U. Nascidos na era digital: entendendo a primeira geração dos nativos digitais. Artmed, 2011.

Pessoa, R. (2020). Os desafios dos docentes em tempos de pandemia e de novas tecnologias de ensino. Ascom Adufg- Sindicato - noticias. https://www.adufg.org.br/noticias/2-noticias/8696-artigo-os-desafios-dos-docentes-em-tempos-de-pandemia-e-de-novas-tecnologias-de-ensino". coloquem em itálico "scom Adufg- Sindicato - noticias.

Sampaio, R. M. (2020) Práticas de ensino e letramentos em tempos de pandemia da COVID-19. Research, Society and Development, 9(7), e519974430. 10.33448/rsd-v9i7.4430. https://www.rsdjournal.org/index.php/rsd/article/view/4430

Thadei, J. Mediação e educação na atualidade: um diálogo com formadores de professores. In: Bacich, L., Moran, J. (Org.) Metodologias ativas para uma educação inovadora: uma abordagem teórico-prática. Porto Alegre: Editora Penso, 2018. 90-105.

Vergara, S. C. (1995). Projetos e relatórios de pesquisa em administração. (3a ed.), Atlas, 2000. Nacionalidade dos autores referenciados na literatura brasileira sobre organizações. Revista Brasileira de Administração Contemporânea. ANPAD: 